This item was submitted to Loughborough's Research Repository by the author.

Items in Figshare are protected by copyright, with all rights reserved, unless otherwise indicated.

\title{
Optimal technique for maximal forward rotating vaults in men's gymnastics
}

PLEASE CITE THE PUBLISHED VERSION

http://dx.doi.org/10.1016/j.humov.2015.05.006

\section{PUBLISHER}

(c) Elsevier

\section{VERSION}

AM (Accepted Manuscript)

\section{PUBLISHER STATEMENT}

This work is made available according to the conditions of the Creative Commons Attribution-NonCommercialNoDerivatives 4.0 International (CC BY-NC-ND 4.0) licence. Full details of this licence are available at: https://creativecommons.org/licenses/by-nc-nd/4.0/

\section{LICENCE}

CC BY-NC-ND 4.0

\section{REPOSITORY RECORD}

Hiley, Michael, Monique I. Jackson, and Fred Yeadon. 2015. "Optimal Technique for Maximal Forward Rotating Vaults in Men's Gymnastics”. Loughborough University. https://hdl.handle.net/2134/18991. 
Human Movement Science 41, 1730-1735, 2015

\title{
Optimal technique for maximal forward rotating vaults in men's gymnastics
}

\author{
Michael J. Hiley, Monique I. Jackson and Maurice R. Yeadon
}

School of Sport, Exercise and Health Sciences, Loughborough University, Loughborough LE11 3TU, UK

Keywords: computer simulation; optimisation; rotation potential

\begin{abstract}
In vaulting a gymnast must generate sufficient linear and angular momentum during the approach and table contact to complete the rotational requirements in the post-flight phase. This study investigated the optimisation of table touchdown conditions and table contact technique for the maximisation of rotation potential for forwards rotating vaults. A planar seven-segment torque-driven computer simulation model of the contact phase in vaulting was evaluated by varying joint torque activation time histories to match three performances of a handspring double somersault vault by an elite gymnast. The closest matching simulation was used as a starting point to maximise post-flight rotation potential (the product of angular momentum and flight time) for a forwards rotating vault. It was found that the maximised rotation potential was sufficient to produce a handspring double piked somersault vault. The corresponding optimal touchdown configuration exhibited hip flexion in contrast to the hyperextended configuration required for maximal height. Increasing touchdown velocity and angular momentum lead to additional post-flight rotation potential. By increasing the horizontal velocity at table touchdown, within limits obtained from recorded performances, the handspring double somersault tucked with one and a half twists, and the handspring triple somersault tucked became theoretically possible.
\end{abstract}

\section{INTRODUCTION}

In the handspring group of vaults the gymnast rotates forwards onto the vaulting table in the pre-flight phase and continues this forwards rotation during the contact and post-flight phases. Over the past 30 years competition performances of this type of vault have increased in difficulty from the handspring (Figure 1a) to the handspring somersault (Figure 1b) to the handspring double somersault (Figure 1c). The additional somersault rotation in post-flight necessitates greater vertical velocity and angular momentum at takeoff from the vaulting table.

The approach run and takeoff from the springboard are used to generate linear and angular momentum in the pre-flight phase. During the contact with the vaulting table horizontal velocity and angular momentum about the mass centre decrease by around 30\% and 40\% respectively for the handspring (Takei, 1989), the handspring somersault (Takei \& Kim, 1990), and the handspring double somersault (Takei, Dunn \& Blucker, 2003). In order to realise the greater vertical takeoff velocities and angular momenta needed for greater post-flight rotation either the initial pre-flight values must be increased or the losses during table contact must be reduced.

Since the amount of rotation in post-flight will be proportional to both angular momentum and flight time for a given body configuration, the product of angular momentum and flight time enables the potential rotation to be quantified in terms of the number of straight somersaults (with arms adducted) that could be achieved in post-flight (Hiley and Yeadon, 2008). While optimisation studies have been carried out to determine technique for maximising performance scores for vaults with fixed 
rotation potential (Gervais, 1994; Koh, Jennings, Elliott \& Lloyd, 2003; Yeadon, Jackson \& Hiley, 2014), the maximisation of rotation potential in vaulting has not been investigated.

The typical touchdown configuration for the handspring double somersault vault (Figure 1c) is similar (hips hyperextended and an angle at the shoulder) to the optimal configuration for maximising height in the straight handspring somersault (Yeadon et al., 2014). Whether the same kind of configuration is optimal for the maximisation of rotation potential is open to question.

Yeadon et al. (2014) compared the contributions of initial touchdown conditions and table contact technique to the maximised post-flight height of a straight handspring somersault since there were conflicting opinions in the coaching literature. It was found that initial conditions and contact technique made equal contributions. It might be expected that the relative contributions to the maximised rotation of a handspring somersault style vault would also be similar in magnitude. Additionally Yeadon et al. (2014) found that increasing touchdown velocity and angular momentum lead to additional post-flight height and therefore to additional rotation potential. Given the limits of the approach run and the generation of angular momentum from the springboard, it might be asked what vaults are possible using optimal technique to maximise rotation potential.

The aims of this study were to: (a) optimise touchdown orientation and configuration together with contact technique in order to maximise rotation potential in forward rotating vaults, (b) compare the contributions of touchdown conditions and contact technique, (c) identify realistic limiting vaults.

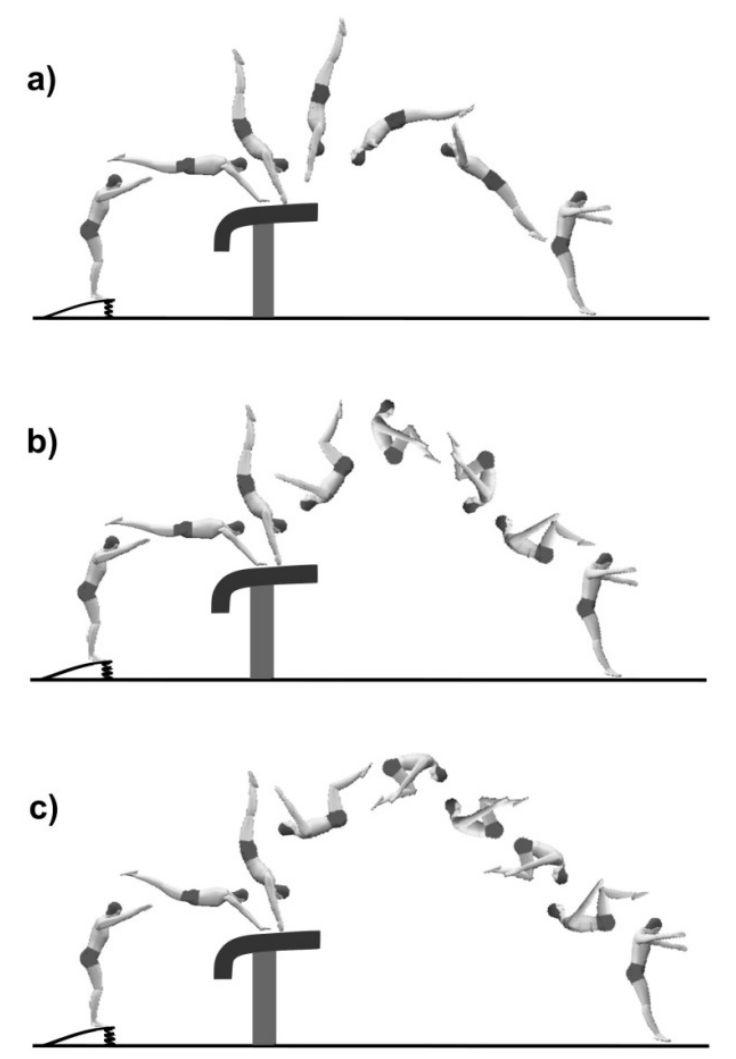

Figure 1. The (a) handspring vault, (b) handspring somersault vault and (c) handspring double somersault vault. 


\section{METHODS}

In order to optimise rotation potential in forwards rotating vaults a torque-driven computer simulation model was used (Yeadon et al., 2014). Subsections in methods describe data collection on an elite gymnast, the simulation model of gymnast and vaulting table, the method of model evaluation, and the application of the model.

\section{Data Collection}

An internationally competitive male gymnast (21 years, $69.9 \mathrm{~kg}, 1.73 \mathrm{~m}$ ) gave informed consent to perform six handspring double somersault vaults (Figure 1c). Eighteen Vicon MX13 cameras, sampling at $480 \mathrm{~Hz}$, were used to track the motion of 58 markers attached to the gymnast and 42 markers attached to the vaulting table. An international Brevet judge assessed and ranked the performance of each vault, with the best three vaults selected for subsequent analysis. The kinematic data were processed using a chain model and global optimisation procedure, similar to that used by Begon, Wieber \& Yeadon (2008), to determine the motion of both the gymnast and the table during the table contact phase of each vaulting trial. The three-dimensional gymnast chain model comprised 12 segments corresponding to head + upper trunk, lower trunk and left and right thighs, shanks, arms, palms and fingers, while the table was also included as a single segment. Upper trunk movement was expressed as a function of hip angle as in Yeadon (1990a) and glenohumeral joint centre movement was a function of shoulder angle similar to Begon et al. (2008). Shoulder protraction/retraction was included by allowing the arm length to change. Upper trunk orientation was determined along with hip angle, knee angle, shoulder angle, wrist angle, knuckle angle, the amount of shoulder retraction/protraction and table position and orientation by minimising the distances between the chain model determined marker coordinates and the recorded marker coordinates. The processed kinematic data were fitted using quintic splines (Wood and Jennings, 1979) in order that derivatives and interpolated values could be obtained.

Gymnast-specific active torque parameters were calculated from measurements taken from the gymnast using a Con-trex isovelocity dynamometer (Yeadon et al., 2014). Torque surfaces were fitted to the data based on the relationships between torque, angle and angular velocity as detailed in Forrester, Yeadon, King \& Pain (2011). The torque data were scaled to the recorded performances using the method of King, Kong \& Yeadon (2009). Since there is no guarantee that maximal torque on a dynamometer will be the same as maximal torque during vaulting, this procedure ensures that the torque parameters are appropriate for vaulting. Gymnast-specific passive torque-angle data were also obtained using the isovelocity dynamometer for shoulder flexion, wrist extension and hip extension. The dynamometer angle was slowly increased $\left(2^{\circ} \mathrm{s}^{-1}\right)$ until the gymnast reached the limit of range of motion. Exponential equations were then fitted to the joint angle/torque data (Esteki \& Mansour, 1996; Reiner \& Edrich, 1999).

Ninety-five anthropometric measurements were taken from the gymnast and gymnast-specific segmental inertia parameters were calculated using the model of Yeadon (1990b). The mass and dimensions of the vaulting table were measured and the inertial parameters calculated by approximating the table-top and base-frame using a number of cylindrical and cuboidal elements. 


\section{Simulation Model}

A two-dimensional torque-driven simulation model of gymnastics vaulting was developed using the software package Autolev ${ }^{\top \mathrm{M}}$. A planar model was used since non-twisting vaults are essentially symmetrical about the sagittal plane. The model simulated the interaction between a seven-segment gymnast and a single-segment vaulting table during the table contact phase of the vault. A chain model used segments representing the fingers, the palms, the arms, the head + upper trunk, the lower trunk, the thighs and the shanks (Figure 2). A damped linear spring was used to represent shoulder retraction and protraction, whilst displacement of the glenohumeral joint centre was modelled as a cubic function of the shoulder angle as in Begon et al., (2008). A damped torsional spring was used to represent hand flexion/extension at the knuckles. A non-linear, damped torsional spring allowed the vaulting table to rotate about its centre of rotation (Figure 2).

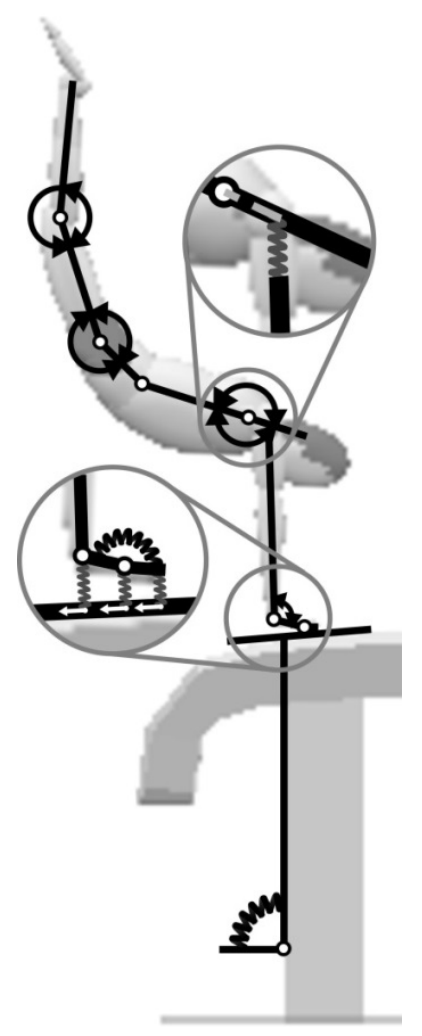

Figure 2. Vaulting table contact phase simulation model.

The interaction between the gymnast and the table was simulated using both static and dynamic Coulomb friction. The normal contact force was represented by spring-dampers situated at three points of contact: the fingertip, the knuckle and the base of the palm, while the tangential contact force was modelled using a two-state frictional force representation to allow for both static and dynamic friction (Jackson, Hiley \& Yeadon, 2011).

The model was driven at each joint by an extensor torque generator and a flexor torque generator, consisting of contractile and series elastic components, which acted at the wrist, shoulder, hip and knee joints. The torque generators were defined based on the measured torque / angle / angular velocity relationship and 
represented the maximum voluntary torques that the gymnast could produce. To determine the applied torque the maximal torque was multiplied by an activation level lying between 0 and 1 (Yeadon et al., 2014). Seven parameters were required to specify the timing and level of activation for each torque generator (two start times, two ramp durations, three activation levels), giving a total of 56 parameters. In addition to the active torque generators, passive torque elements, based on the measured exponential torque-angle relations, were included at the wrist, shoulder and hip joints.

The model parameters (viscoelastic parameters of the shoulder, knuckle, table and contact springs and the static and kinetic coefficients of friction between the hands and the contact surface) were set to those determined in Jackson et al. (2011) apart from the damping parameter of the contact spring, which was increased to $10,000 \mathrm{Nm}^{-2} \mathrm{~s}$ (Table 1) to prevent the hands from 'bouncing' during the initial part of the table contact phase. The input to the torque-driven model comprised the initial conditions at contact (joint angles and velocities, upper trunk angle and velocity, mass centre position and velocity) together with the activation time histories of the torque generators. The output from the torque-driven model comprised the joint angles and the orientation of the upper trunk, the mass centre position and velocity, and the angular momentum about the mass centre.

\begin{tabular}{|c|c|c|}
\hline \multicolumn{3}{|c|}{ Parameter } \\
\hline Table contact stiffness $\left(\mathrm{K}_{\mathrm{cs}}\right)$ & $\left(\mathrm{N} \mathrm{m}^{-1}\right)$ & 153000 \\
\hline Table contact damping ( $\left.D_{\mathrm{cs}}\right)$ & $\left(\mathrm{Ns} \mathrm{m}^{-2}\right)$ & 10000 \\
\hline Knuckle torsional stiffness $\left(\mathrm{K}_{\mathrm{KT}}\right)$ & $\left(\mathrm{Nm} \mathrm{rad}^{-1}\right)$ & 228 \\
\hline Knuckle torsional damping $\left(D_{\mathrm{KT}}\right)$ & $\left(\mathrm{Nms} \mathrm{rad}^{-1}\right)$ & 5.65 \\
\hline Shoulder stiffness $\left(\mathrm{K}_{\mathrm{SH}}\right)$ & $\left(\mathrm{N} \mathrm{m}^{-1}\right)$ & 11300 \\
\hline Shoulder damping $\left(\mathrm{D}_{\mathrm{SH}}\right)$ & $\left(\mathrm{Ns} \mathrm{m}^{-1}\right)$ & 513 \\
\hline Table torsional stiffness $1\left(\mathrm{~K}_{\mathrm{TT} 1}\right)$ & $\left(\mathrm{Nm} \mathrm{rad}^{-1}\right)$ & 145000 \\
\hline Table torsional stiffness $2\left(\mathrm{~K}_{\mathrm{TT2}}\right)$ & $\left(\mathrm{Nm} \mathrm{rad}^{-2}\right)$ & 21100000 \\
\hline Table torsional damping $\left(\mathrm{D}_{T T}\right)$ & $\left(\mathrm{Nms} \mathrm{rad}^{-2}\right)$ & 108 \\
\hline Coefficient of kinetic friction $\left(\mu_{k}\right)$ & & 0.732 \\
\hline Coefficient of static friction $\left(\mu_{\mathrm{s}}\right)$ & & 0.775 \\
\hline
\end{tabular}

\section{Model Evaluation}

To ensure that the torque-driven simulation model produced realistic human movements, an evaluation of the model was conducted by assessing how accurately simulations matched the recorded performances of the three vaults. A genetic algorithm (Carroll, 1996) varied the torque generator activation parameters to minimise an objective function score that quantified the difference between a simulation and a recorded performance (Yeadon et al., 2014). The objective difference score was composed of four performance components $\left(\mathrm{P}_{\mathrm{i}}\right)$, and eight configuration components $\left(\mathrm{C}_{\mathrm{i}}\right)$ : $\mathrm{P}_{1}$ - difference in upper trunk orientation at take-off $\left({ }^{\circ}\right), \mathrm{P}_{2}-\%$ difference in angular momentum at take-off, $\mathrm{P}_{3}-\%$ difference in horizontal linear velocity at take-off, $\mathrm{P}_{4}-\%$ difference in vertical linear velocity at take-off, $\mathrm{C}_{1}$ Root mean square (RMS) difference in wrist angle during contact $\left(^{\circ}\right), \mathrm{C}_{2}-\mathrm{RMS}$ difference in shoulder angle during contact $\left({ }^{\circ}\right), \mathrm{C}_{3}$ - RMS difference in hip angle 
during contact $\left({ }^{\circ}\right), \mathrm{C}_{4}-\mathrm{RMS}$ difference in knee angle during contact $\left(^{\circ}\right), \mathrm{C}_{5}$ difference in wrist angle at take-off $\left(^{\circ}\right), \mathrm{C}_{6}$ - difference in shoulder angle at take-off $\left(^{\circ}\right)$, $\mathrm{C}_{7}$ - difference in hip angle at take-off $\left({ }^{\circ}\right), \mathrm{C}_{8}$ - difference in knee angle at take-off $\left(^{\circ}\right)$. The overall difference score for the simulation was calculated by taking the RMS of the twelve components. The performance and configuration categories were each given a $50 \%$ weighting and within each category the components were equally weighted, where $1^{\circ}$, was considered comparable to a $1 \%$ difference in other measures (Equation 1):

$$
\text { Score }=\sqrt{\left(\frac{P_{1}^{2}+P_{2}^{2}+P_{3}^{2}+P_{4}^{2}}{8}\right)+\left(\frac{C_{1}^{2}+C_{2}^{2}+C_{3}^{2}+C_{4}^{2}+C_{5}^{2}+C_{6}^{2}+C_{7}^{2}+C_{8}^{2}}{16}\right)}
$$

\section{Optimisation}

The simulation model was used to maximise rotation potential in a handspring somersault style vault by manipulating the initial touchdown conditions and table contact technique. The procedure used a parallelised genetic algorithm (van Soest \& Casius, 2003) that was run on a high performance computer with 60 processors. In all optimisations the recommended optimisation algorithm tuning was used except for the selection of single point crossovers (Carroll, 1996). Single point crossovers were chosen as this was deemed more efficient for the optimisation, since sections of activation profiles could then be passed on to the offspring rather than just single parameter values. Penalties were used to ensure the model had an appropriate time of flight to complete the vault.

The post-flight time, $t_{\mathrm{pf}}$, was defined as the time from the last instant of take-off from the table until the first instant of landing. A fixed touchdown angle at landing of $35^{\circ}$ short of vertical was used, as this was the optimum angle found by (King, Yeadon \& Kerwin, 1999) and was close to the mean value of $34^{\circ}$ for handspring somersault vaults (Takei and Kim, 1990). The corresponding height of the mass centre of the model at landing was calculated to be $0.74 \mathrm{~m}$ and was used in all optimisation simulations for consistency. The peak post-flight height and time were then calculated using constant acceleration equations.

The calculation of rotation potential took into account the body orientation at take-off, $\phi_{\text {to }}$, from the vaulting table, as well as the angular momentum at take-off and the post-flight time. The body orientation angle at take-off was calculated from the relative positions of the fingers and the centre of mass at take-off. The rotation potential angle for post-flight, $\phi_{\mathrm{pf}}$, was calculated (Equation 2) as the product of the angular momentum about the mass centre at take-off, $\mathrm{H}$, and the post-flight time, $\mathrm{t}_{\mathrm{pf}}$, divided by the moment of inertia about the centre of mass of the gymnast in a straight position with adducted arms, $I_{\mathrm{cms}},\left(10.7 \mathrm{~kg} \cdot \mathrm{m}^{2}\right)$. The rotation potential, $\phi$, was the sum of the body orientation angle at take-off and the post-flight phase rotation potential expressed in straight somersaults (Equation 3):

$$
\begin{aligned}
& \phi_{\mathrm{pf}}=\frac{H \mathrm{t}_{\mathrm{pf}}}{\mathrm{I}_{\mathrm{cms}}} \\
& \phi=\frac{\phi_{\mathrm{to}}+\phi_{\mathrm{pf}}}{2 \pi}
\end{aligned}
$$




\section{Optimisations using recorded pre-flight performance}

Three optimisations were carried out in order to maximise rotation potential under different conditions. In the first optimisation the table touchdown configuration (shoulder and hip angle) and orientation (torso angle) were varied whilst maintaining the pre-flight parabola and angular momentum of the recorded performance. The shoulder angle was allowed to vary from $90^{\circ}$ to $180^{\circ}$, the hip angle from $40^{\circ}$ of flexion to $40^{\circ}$ of hyperextension and the torso angle from $35^{\circ}$ below to $50^{\circ}$ above the horizontal. In the first optimisation the torque generator activations obtained from the matching simulation were used. The second optimisation used the touchdown configuration and orientation from the recorded performance and the torque generator activation parameters were varied in order to determine the potential improvement arising from contact phase technique changes for the same touchdown conditions. In the third optimisation both the configuration and torque generator activation parameters were allowed to vary in order to maximise post-flight rotation potential. Again the model was constrained to stay on the parabola defined by the gymnast's horizontal and vertical velocity at springboard take-off.

Additionally three sets of simulations were run, assuming the same touchdown orientation and configuration, and contact phase technique obtained from the third optimisation but with increasing horizontal and vertical touchdown velocities and angular momentum about the mass centre in order to determine the effect of changes in touchdown velocities around the third optimisation. All three touchdown parameters were increased to $115 \%$ of the touchdown values of the third optimisation.

\section{Optimisations using increased horizontal pre-flight velocity}

In order to investigate limiting vaults estimates of maximal horizontal pre-flight velocity in handspring double front somersault vaults were obtained from Takei et al. (2003) since horizontal velocity at touchdown appeared to have the greatest effect on post-flight rotation potential. The horizontal velocity at table contact from Takei et al. (2003) was $5.26 \pm 0.25 \mathrm{~ms}^{-1}$ while the horizontal velocity at table contact for the gymnast in the present study was $5.27 \mathrm{~ms}^{-1}$. Two further optimisations (optimisation 4 and optimisation 5) of touchdown configuration and table contact technique were performed. In the first the initial horizontal velocity was increased to $5.52 \mathrm{~ms}^{-1}$ (i.e. increased by one standard deviation) and in the second the initial velocity was increased to $5.77 \mathrm{~ms}^{-1}$ (i.e. increased by two standard deviations). Configurations were chosen in post-flight to produce simulations consistent with these values of optimised rotation potential using the simulation model of aerial movement of Yeadon, Atha \& Hales (1990). Takeoff velocity and angular momentum values for these two optimisations were used as initial conditions for the simulation of postflight. Joint angles for the flight phase were manipulated iteratively to produce aerial simulations that landed $35^{\circ}$ short of vertical.

\section{Optimal touchdown configurations}

The optimal touchdown configurations in optimisations 3,4 and 5 differed from the configuration for maximising post-flight height (Yeadon et al., 2014). Ten additional optimisations with fixed rotation potential were performed to compare the maximum post-flight height arising from the two configurations. The bounds on the initial configuration and orientation were set so as to produce one set of solutions with the arms close to being in line with the torso (within $20^{\circ}$ ) and another with an angle at the shoulder as in the recorded performance. The rotation potential was then systematically increased until no further solution was possible. 


\section{RESULTS}

\section{Model evaluation}

Evaluation of the torque-driven model showed close correspondence with the performance data (Figure 3a, b). Overall difference scores of $6.3 \%, 2.2 \%$ and $2.7 \%$ were obtained for the three vaults considered, demonstrating that the torque-driven model was capable of replicating vaulting performance and therefore was suited for subsequent performance optimisation. The closest matching simulation (that of the second vault) was selected as the starting point for the post-flight rotation potential optimisation.

\section{Optimisation}

The post-flight rotation potential of the matching simulation was 1.16 straight somersaults (ss). When the configuration and orientation at touchdown were varied (optimisation 1) the post-flight rotation potential increased to $1.33 \mathrm{ss}$ (Table 2, Figure 3c). When the torque generator activation parameters were varied (optimisation 2), while maintaining the recorded touchdown configuration and orientation, the postflight rotation potential became 1.48 ss (Table 2, Figure 3d). In the third optimisation in which the touchdown configuration and orientation along with the table contact activations were allowed to vary (optimisation 3 ) the post-flight rotation potential increased to 1.60 ss (Table 2, Figure 3e).

Table 2. Table touchdown and take-off variables from the matching and optimised simulations

\begin{tabular}{|c|c|c|c|c|}
\hline Simulation & Matching & Opt1 * & Opt2 ${ }^{+}$ & Opt3 \\
\hline \multicolumn{5}{|l|}{ Touchdown angles } \\
\hline shoulder [ $\left.{ }^{\circ}\right]$ & $128^{\circ}$ & $137^{\circ}$ & $128^{\circ}$ & $180^{\circ}$ \\
\hline hip $\left[^{\circ}\right]$ & $181^{\circ}$ & $192^{\circ}$ & $181^{\circ}$ & $162^{\circ}$ \\
\hline \multicolumn{5}{|l|}{ Touchdown CoM } \\
\hline ver. position [m] & 1.74 & 1.78 & 1.74 & 1.85 \\
\hline ver. velocity $\left[\mathrm{ms}^{-1}\right]$ & 2.95 & 2.81 & 2.95 & 2.56 \\
\hline hor. velocity $\left[\mathrm{ms}^{-1}\right]$ & 5.27 & 5.27 & 5.27 & 5.27 \\
\hline \multicolumn{5}{|l|}{ Take-off angles } \\
\hline torso $\left[{ }^{\circ}\right]$ & $66^{\circ}$ & $81^{\circ}$ & $76^{\circ}$ & $60^{\circ}$ \\
\hline shoulder $\left[{ }^{\circ}\right]$ & $155^{\circ}$ & $194^{\circ}$ & $174^{\circ}$ & $179^{\circ}$ \\
\hline hip $\left[^{\circ}\right]$ & $185^{\circ}$ & $194^{\circ}$ & $200^{\circ}$ & $191^{\circ}$ \\
\hline \multicolumn{5}{|l|}{ Take-off CoM } \\
\hline ver. position [m] & 2.36 & 2.36 & 2.37 & 2.21 \\
\hline ver. velocity $\left[\mathrm{ms}^{-1}\right]$ & 3.54 & 3.39 & 2.92 & 3.24 \\
\hline hor. velocity $\left[\mathrm{ms}^{-1}\right]$ & 3.62 & 3.45 & 3.57 & 3.18 \\
\hline \multicolumn{5}{|l|}{ Post-flight } \\
\hline peak height [m] & 3.00 & 2.95 & 2.81 & 2.76 \\
\hline rot. potential [ss] & 1.16 & 1.33 & 1.48 & 1.60 \\
\hline ang. mom. $\left[\mathrm{ss} . \mathrm{s}^{-1}\right]$ & 1.12 & 1.30 & 1.56 & 1.63 \\
\hline time $[\mathrm{s}]$ & 1.04 & 1.02 & 0.95 & 0.98 \\
\hline
\end{tabular}



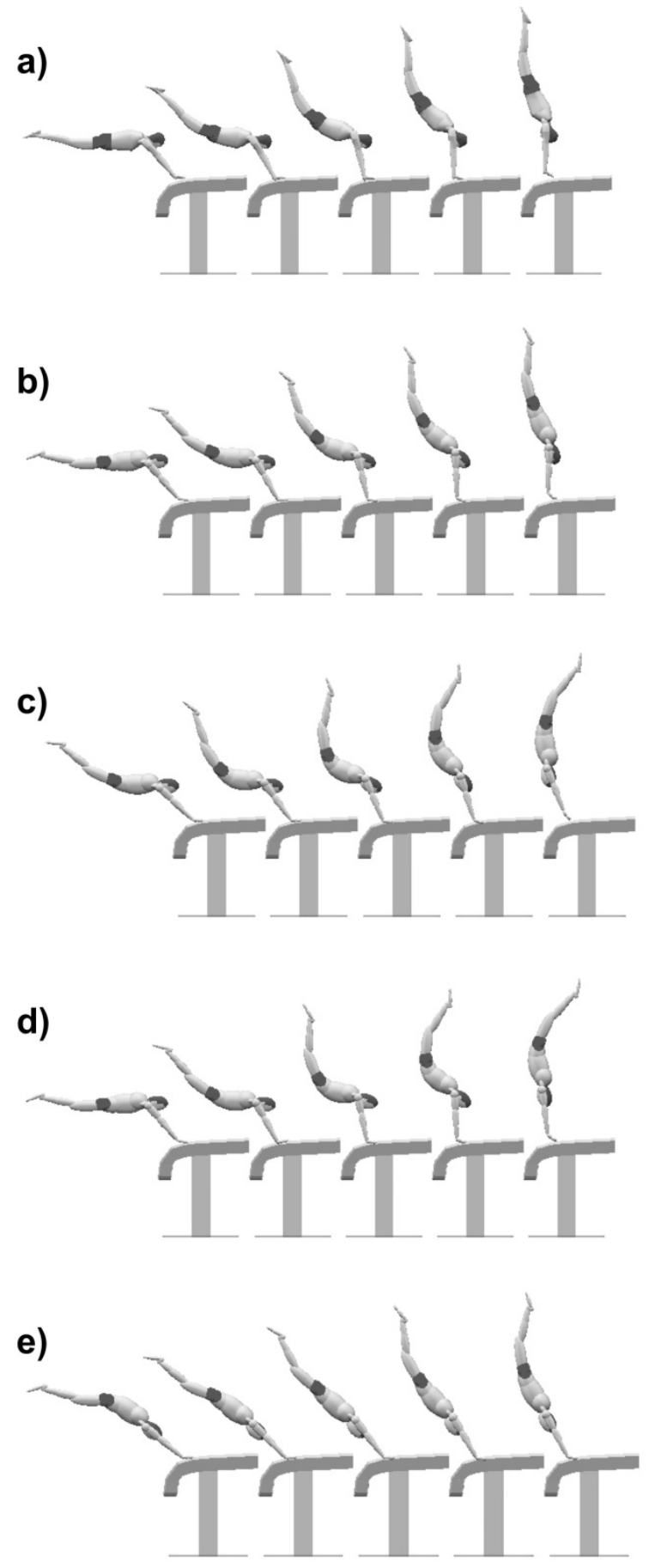

Figure 3. Simulated vaulting performances: (a) recorded performance, (b) matching simulation, (c) optimised touchdown configuration, (d) optimised contact phase technique, and (e) optimised touchdown configuration and contact phase.

The joint torque activations and net joint torques varied considerably for the matched simulation and the three optimisations (Figure 4). For the third optimisation the net joint torques were particularly small. 

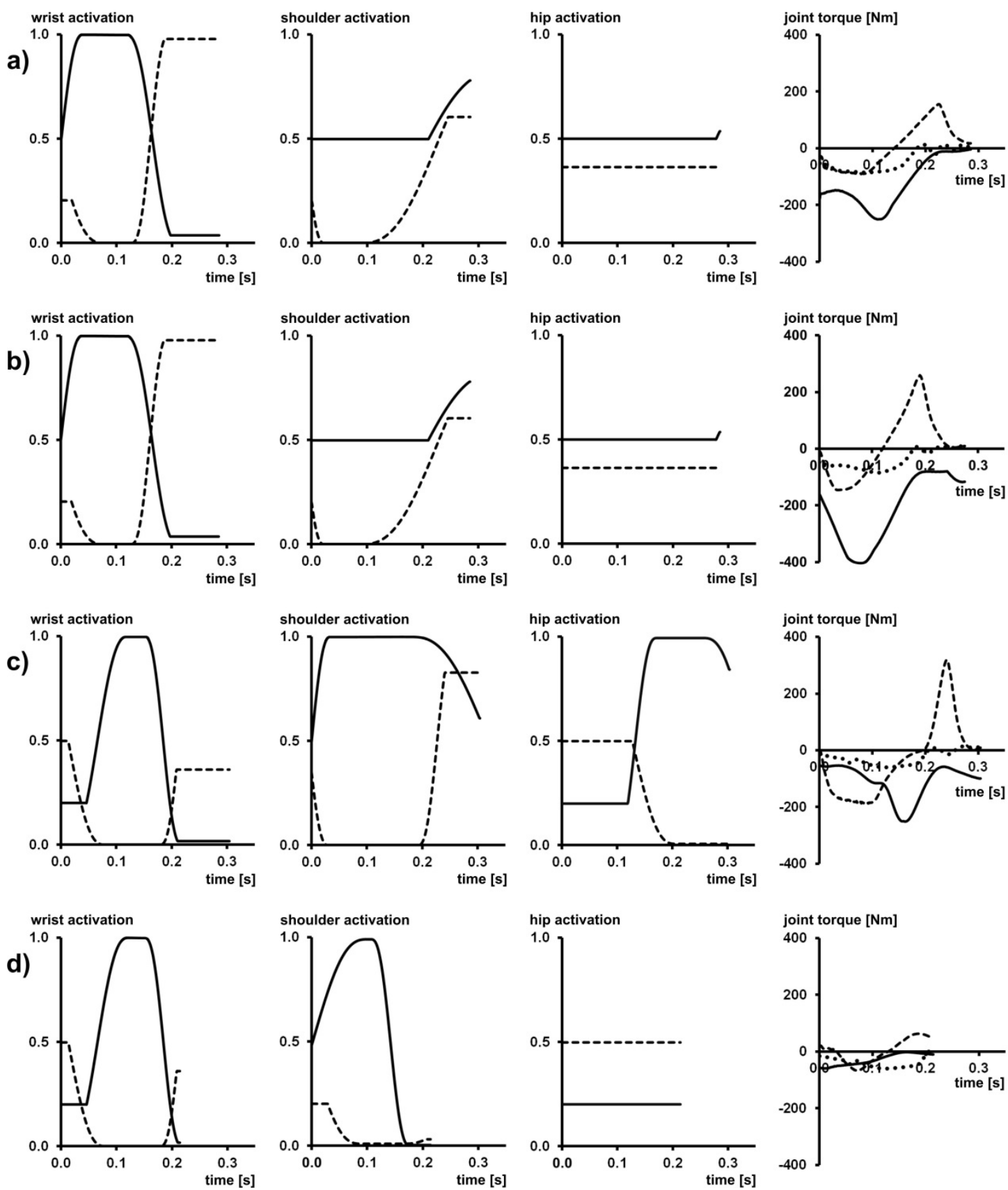

Figure 4. Joint torque activation time histories (flexor: solid line, extensor: dashed line) and net joint torques (wrist: dotted line, shoulder: dashed line, hip: solid line) for (a) matched simulation, (b) optimisation 1, (c) optimisation 2, (d) optimisation 3.

When the touchdown horizontal and vertical velocities and angular momentum were independently increased with the contact technique of optimisation 3, post-flight rotation potential was affected (Figure 5). An increase in horizontal touchdown velocity resulted in an increase of rotation potential (Figure 5a) while increases in vertical velocity and angular momentum at touchdown each produced an initial increase in post-flight rotation potential followed by a decrease (Figures 5b, 5c). 


\section{rotation potential [ss]}



rotation potential [ss]
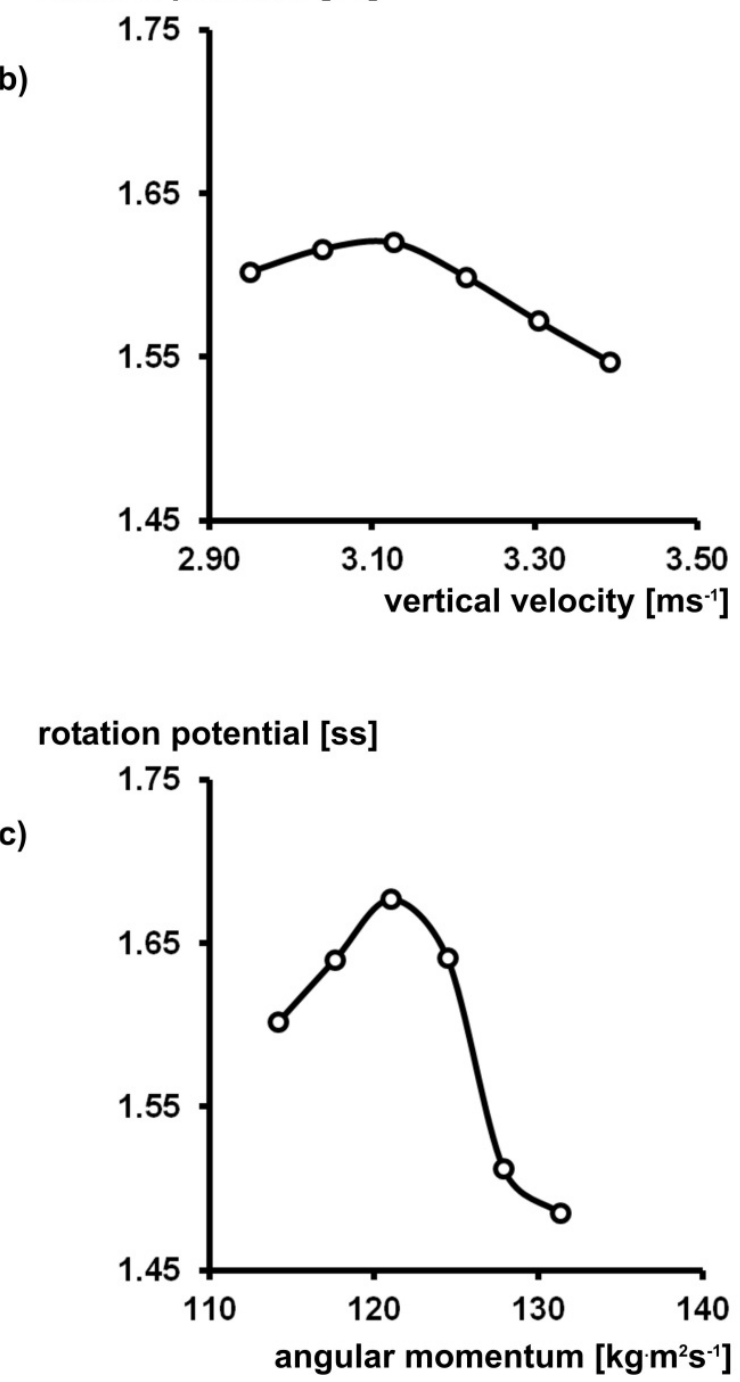

Figure 5. Changes in rotation potential (measured in straight somersaults, ss) when varying touchdown (a) horizontal velocity, (b) vertical velocity and (c) angular momentum respectively from recorded to $115 \%$ of recorded value. 
When the pre-flight horizontal velocity was increased by one and then two standard deviations, the optimised rotation potential increased from 1.60 straight somersaults to $1.65 \mathrm{ss}$ and $1.70 \mathrm{ss}$, respectively. With a post-flight rotation potential of $1.60 \mathrm{ss}$ a handspring double piked somersault vault (a Blanik) could be simulated (Figure 6a). With a rotation potential of 1.65 ss a handspring double piked somersault with half twist (a piked Dragulescu; FIG, 2013) was possible (Figure 6b) and with 1.70 ss a handspring double tucked somersault with one and a half twists or a handspring triple tucked somersault became possible (Figures 6c, 6d).

a)

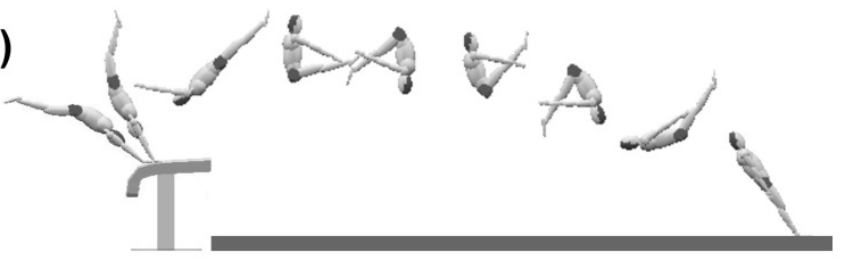

b)

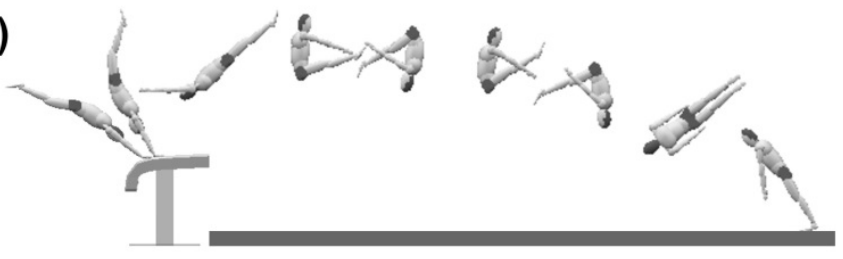

c)

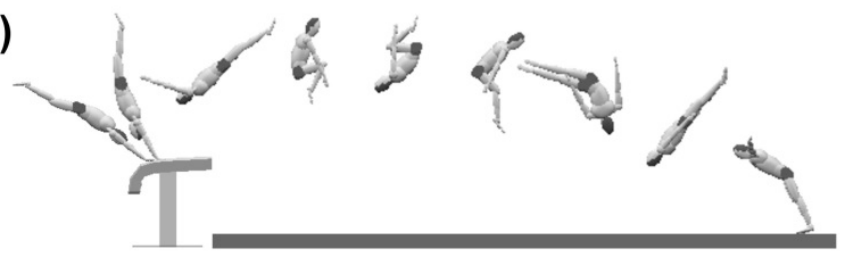

d)

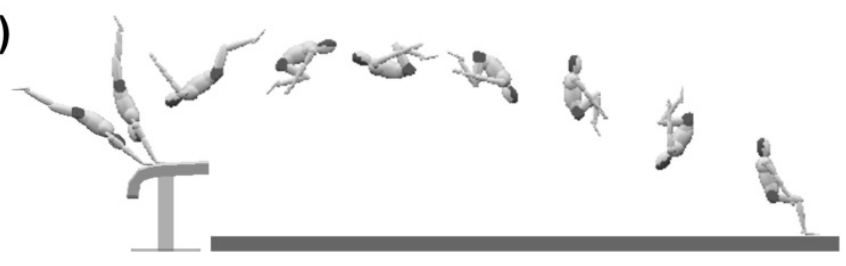

Figure 6. Limiting vaults with maximal post-flight rotation potential: (a) handspring double piked somersault (1.60ss), (b) handspring double piked somersault with half twist (1.65ss), (c) handspring double tucked somersault with $1 \frac{1 / 2}{2}$ twists (1.70ss), (d) handspring triple tucked somersault (1.70ss).

In the comparison of maximum heights arising from the two touchdown configurations the hyper-extended hip and closed shoulder configuration adopted by the gymnast produced a greater peak height for the same rotation potential (Figure 7). 


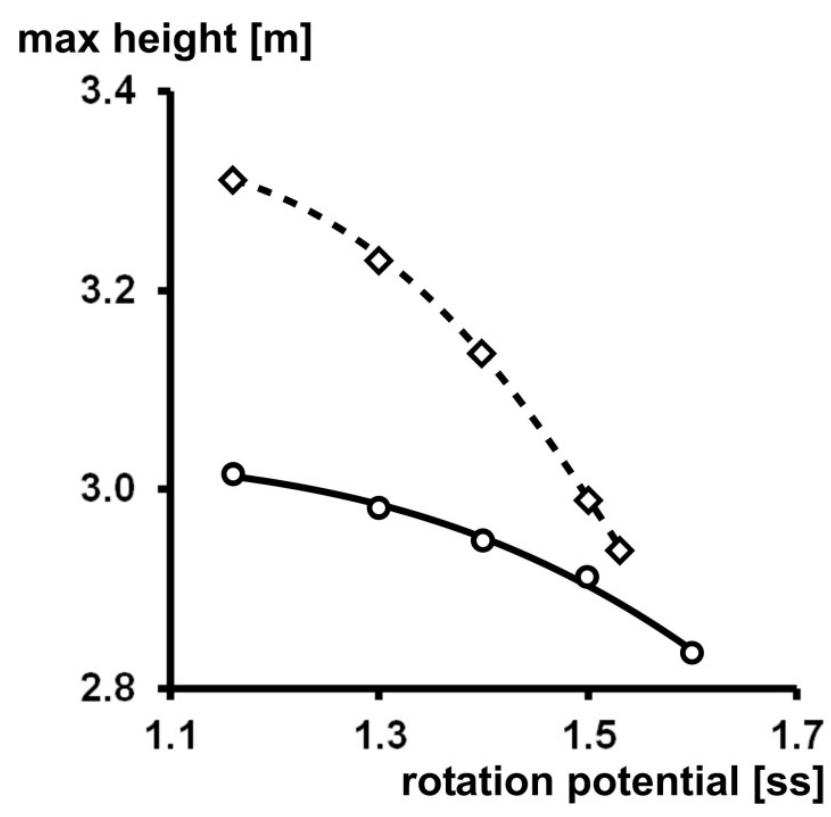

Figure 7. Optimisations for maximum height for a given rotation potential with a) arms in line (circles and solid line) and b) a closed shoulder angle (diamonds and dashed line) at table touchdown.

\section{DISCUSSION}

The first two aims of this study were to investigate the extent to which the conditions at vaulting table touchdown and the technique adopted during table contact affected post-flight rotation potential during a handspring double somersault vault (Roche). The third aim was to determine what limiting vaults would be possible.

Changes in contact technique produce a greater increase (0.32 ss) in post-flight rotation potential than changes in touchdown configuration and orientation (0.17 ss). This contrasts with the results that equal increases in post-flight height are produced by contact technique and touchdown conditions for handspring somersault style vaults with maximised height (Yeadon et al., 2014) and that contact technique makes little contribution to rotation in the Hecht vault (King \& Yeadon, 2005). When there is an angle at the shoulder at touchdown there is a tendency for the shoulder angle to close. As a consequence in the Hecht vault the shoulder torque will be in concentric mode and only relatively small torque can be exerted. On the other hand in the handspring somersault in which the shoulder angle opens during the contact phase, the shoulder torque will be in eccentric mode and large torque can be exerted. The greater contribution from contact technique for maximising rotation potential in forward rotating vaults may be a consequence of being able to benefit directly from a reduction in the loss in angular momentum.

The shoulder torque activation time history showed full flexion activation for optimisations 2 and 3 compared to the sub-maximal activation of the matching simulation (Figure 4). The hip flexor activation time history for optimisation 2 also showed full activation whereas in optimisation 3 which adopted initial hip flexion at touchdown hip activation was low (Figure 4). In optimisation 3 the net joint flexor torque at the shoulder was low despite full activation being reached, presumably due to the shoulder being near the limit of range of movement. Thus the optimal table contact technique is very dependent upon the initial touchdown configuration and orientation. 
The increases in rotation potential of the three optimised vaults were achieved through a reduction in the loss of angular momentum during the contact phase. In the recorded performance of the Roche vault (handspring double somersault) the loss of angular momentum from pre-flight to post-flight was 32\% whereas the losses in optimisations 1, 2 and 3 were $23 \%, 8 \%$ and $4 \%$ respectively. In all three optimisations peak height of the mass centre in post-flight was lower than in the recorded performance (Table 2). Smaller losses in angular momentum from preflight to post-flight can be achieved but at the cost of peak post-flight height. The same trend can be seen in a comparison of handspring and handspring somersaults vaults where the angular momentum losses during contact were 53\% and $32 \%$ respectively (Takei, 1989; Takei \& Kim, 1990). In contrast for performances of the handspring double somersault the loss of angular momentum was 40\% (Takei et al., 2003). This is a puzzling result. The post-flight angular momenta values of the handspring double somersault were $12 \%$ smaller than for the handspring somersault whereas vertical takeoff velocities from the vaulting table were $27 \%$ greater corresponding to around $13 \%$ more flight time. Thus the combined effect of changes in angular momentum and flight time essentially cancel out. If this is correct then the additional rotation must have been a result of different configuration in the flight phase. While this must be part of the explanation, it seems unlikely that configurational change alone could account for an additional somersault.

For a given submaximal amount of rotation potential the hyper-extended hip and closed shoulder configuration adopted by the gymnast was capable of producing a greater peak post-flight height. However, it was not capable of producing as much rotation potential at its limit (1.53 ss versus $1.60 \mathrm{ss}$, Figure 7). Therefore, in terms of producing rotation potential there are two techniques that can be used. The majority of elite gymnasts adopt an arched technique similar to that used by the gymnast in the present study. This is not surprising given that Takei et al. (2003) demonstrated that for higher scoring Roche vaults the peak height of the mass centre in post-flight was significantly higher than for the lower scoring vaults. However, if maximal amounts of rotation potential are required for limiting vaults then a change in technique may be required.

The choice between opening the hip angle versus opening the shoulder angle for maximum rotation may be dependent upon the relative strengths of maximal hip and shoulder torques. Thus the result obtained for the gymnast parameters used in this study may or may not apply to elite gymnasts in general. This is a limitation of the study.

The simulations presented in this paper demonstrate that changes in initial conditions and contact technique both have an influence on post-flight rotation potential. Increasing horizontal approach velocity will improve performance in agreement with Takei (1988). However in the current optimal solution the arms are in line with the torso at table touchdown and so the gymnast would need to modify his technique in order to achieve maximal rotation potential. Increasing both vertical velocity and angular momentum at table touchdown will improve performance up to point.

The optimisation based upon the recorded initial conditions allowed a handspring double piked somersault (a Blanik, Figure 6a) to be simulated. An increase in the horizontal pre-flight velocity of $0.25 \mathrm{~ms}^{-1}$ allowed an additional half twist to be added (a piked Dragalescu, Figure 6b). A further increase of $0.25 \mathrm{~ms}^{-1}$ enabled a handspring double tucked somersault with $1 \frac{1}{2}$ twists (Figure 6c) or a 
handspring triple tucked somersault (Figure $6 \mathrm{~d}$ ) to be simulated. These last two vaults should be considered to be the limiting vaults in the handspring group in that they are theoretically possible but anything more difficult is unlikely to ever be achieved.

\section{ACKNOWLEDGEMENTS}

The authors wish to thank British Gymnastics and Loughborough University for their support.

\section{CONFLICT OF INTEREST STATEMENT}

The authors wish to disclose that they have no financial or personal relationships with any people or organisations that could inappropriately influence this work.

\section{REFERENCES}

Begon, M., Wieber, P-B., \& Yeadon, M.R. (2008). Kinematics estimation of straddled movements on high bar from a limited number of skin markers using a chain model. Journal of Biomechanics, 41, 581-586.

Carroll, D.L. (1996). Genetic Algorithms and Optimizing Chemical Oxygen-lodine Lasers. In: Wilson, H.B., Batra, R.C., Bert, C.W., Davis, A.M.J., Schapery, R.A., Stewart, D.S., Swinson, F.F. (Eds), Developments in Theoretical and Applied Mechanics (pp. 411-424). The University of Alabama.

Esteki, A., \& Mansour, J. M. (1996). An experimentally based nonlinear viscoelastic model of joint passive moment. Journal of Biomechanics, 29, 443-50.

Fédération Internationale de Gymnastique - FIG. (2013). Code of Points Men's Artistic Gymnastics.

Forrester, S. E., Yeadon, M.R., King, M.A., \& Pain, M.T.G. (2011). Comparing different approaches for determining joint torque parameters from isovelocity dynamometer measurements. Journal of Biomechanics, 44, 955-961.

Gervais, P. (1994). A prediction of an optimal performance of the handspring $1 \frac{1}{2} 2$ front salto longhorse vault. Journal of Biomechanics, 27, 67-75.

Hiley, M.J., \& Yeadon, M.R. (2008). Optimisation of high bar circling technique for consistent performance of a triple piked somersault dismount. Journal of Biomechanics, 41, 1730-1735.

Jackson, M.I., Hiley, M.J., \& Yeadon, M.R. (2011). A comparison of Coulomb and pseudo-Coulomb friction implementations: Application to the table contact phase of gymnastics vaulting. Journal of Biomechanics, 44, 2706-2711.

King, M.A., \& Yeadon, M.R. (2005). Factors influencing performance in the Hecht vault and implications for modelling. Journal of Biomechanics, 38, 145-151.

King, M.A., Kong, P.W., \& Yeadon, M.R. (2009). Determining effective subjectspecific strength levels for forward dives using computer simulations of recorded performances. Journal of Biomechanics, 42, 2672-2677.

King, M.A., Yeadon, M.R., \& Kerwin, D.G. (1999). A two segment simulation model of long horse vaulting. Journal of Sports Sciences, 17, 313-324.

Koh, M., Jennings, L., Elliott, B, \& Lloyd, D. (2003). A predicted optimal performance of the Yurchenko Layout vault in Women's Artistic Gymnastics. Journal of Applied Biomechanics, 19, 187-204. 
Reiner, R., \& Edrich, T. (1999). Identification of passive elastic joint moments in the lower extremities. Journal of Biomechanics, 32, 539-44.

van Soest, A.J., \& Casius, R.L.J. (2003). The merits of a parallel genetic algorithm in solving hard optimiszation problems. Journal of Biomechanical Engineering, 125,141-146.

Takei, Y. (1988). Techniques used in performing the handspring and salto forward tucked in gymnastic vaulting. International Journal of Sport Biomechanics, 4, 260-281.

Takei, Y. (1989). Techniques used by elite male gymnasts performing a handspring vault at the 1987 Pan American Games. International Journal of Sport Biomechanics, 5, 1-25.

Takei, Y., \& Kim, E.J. (1990). Techniques used in performing the handspring and salto forward tucked vault at the 1988 Olympic Games. International Journal of Sport Biomechanics, 6, 111-138.

Takei, Y., Dunn, J.H., \& Blucker, E. (2003). Techniques used in high-scoring and lowscoring 'Roche' vaults performed by elite male gymnasts. Sports Biomechanics, 2, 141-162.

Wood, G.A., \& Jennings, L.S. (1979). On the use of spine functions for data smoothing. Journal of Biomechanics, 12, 477-479.

Yeadon, M.R. (1990a). The simulation of aerial movement - I: The determination of orientation angles from film data. Journal of Biomechanics, 23, 59-66.

Yeadon, M.R. (1990b). The simulation of aerial movement - II. A mathematical inertia model of the human body. Journal of Biomechanics, 23, 67-74.

Yeadon, M.R., Atha, J., \& Hales, F.D. (1990). The simulation of aerial movement - IV: A computer simulation model. Journal of Biomechanics, 23, 85-89.

Yeadon, M.R., Jackson, M.I., \& Hiley, M.J. (2014). The influence of touchdown conditions and contact phase technique on post-flight height in the straight handspring somersault vault. Journal of Biomechanics, 47, 3143-3148. 